\title{
Cytokine profiles in idiopathic pulmonary fibrosis suggest an important role for TGF- $\beta$ and IL-10
}

\author{
A. Bergeron*, P. Soler*, M. Kambouchner", P. Loiseau*, B. Milleron`, D. Valeyre ${ }^{+}$, A.J. Hance*, \\ A. Tazi*,+
}

Cytokine profiles in idiopathic pulmonary fibrosis suggest an important role for TGF- $\beta$ and IL-10. A. Bergeron, P. Soler, M. Kambouchner, P. Loiseau, B. Milleron, D. Valeyre, A.J. Hance, A. Tazi. (C) ERS Journals Ltd 2003.

ABSTRACT: Modulation of cytokine expression represents a potentially useful approach for the treatment of idiopathic pulmonary fibrosis (IPF).

To identify potential targets for such intervention, semi-quantitative reverse transcriptasepolymerase chain reaction was used to compare the expression of messenger ribonucleic acids (mRNAs) coding for 17 cytokines in lung tissue obtained from patients with IPF at the time of diagnosis and control subjects. Some cytokines were also studied at the protein level by immunohistochemical techniques.

mRNAs coding for all of the cytokines evaluated were detected in both control and fibrotic lung samples. Only transforming growth factor (TGF)- $\beta$ and interleukin (IL)10 mRNAs were quantitatively increased in lung biopsies from patients with IPF compared with those of controls, results confirmed at the protein level by immunohistochemistry. Although mRNAs for platelet-derived growth factor (PDGF)-BB and keratinocyte growth factor (KGF) were expressed in similar amounts in lungs from patients with IPF and controls, localised accumulation of both factors was also observed in IPF. Hyperplastic alveolar epithelial cells were a prominent source of cytokines, where IL-10, PDGF-BB and KGF were present in increased amounts, although increased accumulation in fibroblasts, smooth-muscle cells and matrix components was also observed (PDGF-BB, TGF- $\beta$ ).

These results offer new insights into the cytokines produced in the lung in idiopathic pulmonary fibrosis and suggest that modulation of the production of transforming growth factor- $\beta$ and interleukin-10 may represent a potentially useful therapeutic strategy for this disabling disease.

Eur Respir J 2003; 22: 69-76.
*INSERM U 82, Faculté de Médecine Xavier Bichat, Paris, ${ }^{\#}$ Dept of Pathology, Avicenne Hospital, Bobigny, "Dept of Respiratory Medicine, Tenon Hospital, Paris and ${ }^{+}$Dept of Respiratory Medicine, Hôpital Avicenne, Bobigny, France.

\section{Correspondence: A. Tazi}

Service de Pneumologie

Hôpital Avicenne

125 rue de Stalingrad

93009 Bobigny

France

Fax: 33148955126

E-mail: abdellatif.tazi@avc.ap-hop-paris.fr

Keywords: Cytokines

idiopathic pulmonary fibrosis

immunohistochemistry

polymerase chain reaction

Received: February 212002

Accepted after revision: February 162003
Idiopathic pulmonary fibrosis (IPF), also called cryptogenic fibrosing alveolitis, is a progressive inflammatory and fibrotic lung disease of unknown cause characterised by the remodelling of the architecture of the lung parenchyma and collagen deposition [1-4]. In patients whose lung biopsy shows the characteristic histological pattern of IPF, usual interstitial pneumonia (UIP), the disease generally follows an unfavourable course leading to death in most patients [2, 3].

Pulmonary fibrosis typically results from a reaction to lung injury. In IPF, it is generally accepted that an unknown triggering agent damages alveolar epithelial and endothelial cells and disrupts the alveolar basement membrane. Rather than healing this initial injury, the ensuing inflammatory reaction leads to further damage, which perpetuates the inflammatory response and ultimately leads to progressive pulmonary fibrosis, remodelling of the lung architecture and impairment of gas exchange $[3,5]$. Studies performed in both animal models of pulmonary fibrosis and in humans with fibrotic lung disease have shown that various cytokines are produced locally in the course of these processes, and it is thought that these cytokines may participate in various steps of the pathogenesis of pulmonary fibrosis [3, 5-7].

Several groups have evaluated the production of cytokines in the lungs of patients with IPF. Although it has been suggested that some of these mediators, particularly transforming growth factor (TGF)- $\beta$, platelet-derived growth factor (PDGF) and tumour necrosis factor (TNF)- $\alpha$, could be important in the pathogenesis of this disorder [3, 5, 7], the precise role of these cytokines remains to be firmly established. Studies using animal models of pulmonary fibrosis have suggested that a number of other mediators are potentially involved in fibrotic lung reactions $[5,6]$. These results, however, cannot be easily extrapolated to patients with IPF, because the cytokine(s) identified as being critical for lung fibrosis are different in other animal models and because none of these animal models give rise to a pattern of histopathological abnormalities similar to that observed in IPF [6, 8].

Since no satisfactory treatment is currently available for IPF, the evaluation of the therapeutic effects of the modulation of cytokine production in this disease represents a potentially important field of investigation [9]. In this regard, an essential first step is to precisely and comprehensively characterise the profile of cytokine production in the lung parenchyma of patients with IPF at the time diagnosis is established, in order to identify potential cytokine targets for new therapeutic strategies. In this study, the reverse transcriptase-polymerase chain reaction (RT-PCR) has been used to evaluate the expression of messenger ribonucleic acid (mRNA) for 17 different 
cytokines in lung tissue obtained from patients with IPF and from control subjects. Some of the cytokines that are thought to be of critical importance in tissue fibrosis were also studied at the protein level by immunohistochemical techniques.

\section{Materials and methods}

\section{Tissue specimens}

Patients with idiopathic pulmonary fibrosis. Open lung biopsies were obtained from five patients with IPF at the time of histological confirmation of the diagnosis. All patients (three males, two females; mean age $58 \pm 14$ yrs; three smokers, two nonsmokers) had clinical signs and symptoms consistent with the diagnosis of IPF, which included the presence of dyspnoea on exertion, cough of insidious onset and inspiratory velcro rales on chest examination. In all cases, high-resolution computed tomography of the lungs showed the association of linear and reticular opacities with honeycombing predominating in subpleural regions and at the lung base [2]. Pulmonary function tests were as follows: total lung capacity $68 \pm 13 \%$ predicted, vital capacity $74 \pm 20 \%$ pred, residual volume (RV) $68 \pm 14 \%$ pred, forced expiratory volume in one second/forced vital capacity $88 \pm 16 \%$ pred, single-breath diffusing capacity $53 \pm 11 \%$ pred. None of the patients had symptoms of systemic disease and none had received any treatment for pulmonary fibrosis prior to lung biopsy.

Control subjects. Lung tissue obtained from five patients (three males, two females; mean age $55 \pm 9$ yrs; three smokers, two nonsmokers) who underwent thoracic surgery for localised primary lung carcinoma $(n=3)$, localised bronchiectasis $(n=1)$ or isolated carcinoid tumour $(\mathrm{n}=1)$ were used as control specimens. In all cases, lung tissue was taken at a site distant from the pathological process and gross pathological inspection was normal.

\section{Morphological assessment of lung tissue}

Fragments of lung biopsies were immediately frozen and stored in liquid nitrogen. The same tissue fragment of each biopsy was used for morphological assessment, isolation of RNA and immunohistochemical techniques. A second tissue fragment was fixed in Bouin-Hollande solution, processed by routine techniques and used for diagnostic purposes.

Cryostat sections taken at three different levels from each fragment (the two extremities and the centre of the sample) were stained with haematoxylin, eosin and safranin for light microscopic evaluation. Histopathological features were evaluated by two pathologists (P. Soler and M. Kambouchner) and the abnormalities in the three sections from a given biopsy were found to be comparable for all samples evaluated in this study.

To quantify collagen deposition in biopsies from patients and controls, the amount of type I and III collagen present was determined using the Picro Sirius red staining method, as described previously [10]. Frozen sections were then observed by microscopy under polarising light using an image analysis system (Microvision; Histolab, Evry, France). The entire surface of each tissue section (IPF: $7.6 \pm 2.6 \mathrm{~mm}^{2}$; controls: $7.7 \pm 3 \mathrm{~mm}^{2}$ ) was visualised and areas stained in red (corresponding to collagen) were outlined, permitting the determination of the percentage of the total tissue surface area occupied by collagens $(35.4 \pm 23.5 \%$ and $6.7 \pm 2.4 \%$ in IPF and control specimens, respectively).

\section{$R T-P C R$ procedure}

Total RNA was isolated from each sample using RNAzol (Bioprobe Systems, Montreuil sous Bois, France), quantified by measurement of absorbance at $260 \mathrm{~nm}$ and retrotranscribed into complementary deoxyribonucleic acid (cDNA), as described previously [11]. To permit the comparison of cytokine mRNAs in different samples by RT-PCR, it was important that equivalent amounts of total cDNA from each specimen were used for the amplification reactions. Thus, total cDNA was first quantified based on the amount of cDNA coding for the abundant ribosomal protein S14, as described previously [11].

Aliquots of cDNA from each sample containing equivalent amounts of cDNA were used for the amplification of cytokine cDNAs by PCR. For each cytokine, all samples were amplified and processed in parallel, as described previously [11]. Reaction mixtures (final volume $100 \mu \mathrm{L}$ ) contained: $20 \mathrm{mM}$ Tris- $\mathrm{HCl}$ (pH 8.4), $50 \mathrm{mM} \mathrm{KCl}, \mathrm{MgCl}_{2}$ (1.75 mM for most cytokines, $1.5 \mathrm{mM}$ for granulocyte-macrophage colony-stimulating factor (GM-CSF), interleukin (IL)-6, insulin growth factor (IGF)-2 and epithelial growth factor (EGF)), $200 \mu \mathrm{M}$ each dNTP, 10 pmol of each oligonucleotide primer (table 1), $2.5 \mathrm{U}$ Taq polymerase (Life Technologies, Gaithersburg, MD, USA) and cDNA. Cycling parameters were as follows: denaturation, $95^{\circ} \mathrm{C}$ for $1 \mathrm{~min}$; annealing, $60^{\circ} \mathrm{C}$ (for GM-CSF, IL-6, IGF-2, $\mathrm{EGF}$ ) or $55^{\circ} \mathrm{C}$ (all other cytokines) for $1 \mathrm{~min}$; extension, $72^{\circ} \mathrm{C}$ for $1 \mathrm{~min}$. To ensure that samples obtained during the exponential phase of the amplification reaction could be analysed, $20 \mu \mathrm{L}$ aliquots from each reaction mixture were removed on four occasions during amplification, while the thermocycler was maintained at $72^{\circ} \mathrm{C}$. The reaction was interrupted after $25,30,35$ and 40 cycles (for TGF- $\beta$, keratinocyte growth factor (KGF), IL-8 and IGF-2) or after $30,35,40$ and 45 cycles (all other cytokines). To ensure that only specific amplification products were formed and to determine the number of cycles corresponding to the exponential phase of the amplification, an aliquot of each reaction was initially electrophoresed into $2 \%$ agarose gels and visualised under ultra violet illumination after ethidium bromide staining.

To quantify the expression of a given cytokine in the different samples, $10 \mu \mathrm{L}$ aliquots of the amplification products obtained at two successive times during the exponential phase of the PCR reaction were applied to Hybond-N nylon membranes (Amersham Corp., Arlington Heights, IL, USA) in a dot blot format, as described previously [11]. For each cytokine, dot blots were then hybridised with a radiolabelled oligonucleotide probe complementary to a sequence within the amplified fragment (table 2, fig. 1). The radioactivity bound was determined using electronic autoradiography (Instant Imager; Packard, Meriden, CT, USA) and results expressed as counts per minute. The aliquots taken at the two different times during the exponential phase of the amplification reaction were analysed separately but gave comparable results.

\section{Immunohistochemical techniques}

Monoclonal antibodies used in this study were: anti-GMCSF (Genzyme, Cambridge, MA, USA); anti-IL-10 (JES312G8: Pharmingen, San Diego, CA, USA); antihuman TGF- $\beta$ (Serotec, Oxford, UK); anti-TGF- $\alpha$ (Serotec); anticytokeratin (Immunotech, Marseille, France). Immunoglobulin (Ig)G1 (MOPC 21) and IgG2 (MOPC 141) control antibodies (Sigma, Saint Louis, MO, USA) were used to assess nonspecific binding. Purified polyclonal antibodies were used to detect the expression of human KGF and PDGF-BB (R\&D, Abingdon, UK). 
Table 1. - Sequences of primer pairs used for amplification and identification of cytokine complementary deoxyribonucleic acid Cytokine Primer pairs

\begin{tabular}{|c|c|c|}
\hline IL-1 $\beta$ & 5' GCT GAT GGC CCT AAA CAG ATG A & $5^{\prime}$ TTG CTG TAG TGG TGG TCG GAG AT \\
\hline IL-6 & 5' CAG CCA CTC ACC TCT TCA GAA C & 5' GCC TCT TTG CTG CTT TCA CA \\
\hline IL-8 & 5' GAC CAC ACT GCG CCA ACA CAT CT & $5^{\prime}$ TCT CAG CCC TCT TCA AAA ACT \\
\hline IL-10 & 5' TGA TGC CCC AAG CTG AGA ACC & 5' TAG AGT CGC CAC CCT GAT GTC \\
\hline IL-15 & 5' CTG GAA ACC CCT TGC CAT AGC & 5' GCA CTG AAA CAG CCC AAA ATG A \\
\hline IFN- $\gamma$ & 5' CGA GAT GAC TTC GAA AAG CTG ACT & 5' CCT TTT TCG CTT CCC TGT TTT A \\
\hline GM-CSF & 5' GGC GTC TCC TGA ACC TGA GTA G & 5' GTC GGC TCC TGG AGG TCA AA \\
\hline TNF- $\alpha$ & 5' TTG TTC CTC AGC CTC TTC TCC TCC & 5' GAG GGC TGA TTA GAG AGA GGT \\
\hline TGF- $\alpha$ & 5' CCT GTT CGC TCT GGG TAT TGT & 5' GCA CCA ACG TAC CCA GAA TG \\
\hline TGF- $\beta$ & 5' AGT TGT GCG GCA GTG GTT GA & 5' GAA CCC GTT GAT GTC CAC TTG \\
\hline EGF & 5' GGG TGC ACA GCT GTG GAG AGA & $5^{\prime}$ TGG GAC AGG GGA CAT TCA GAG \\
\hline PDGF-A & 5' TCC GTA GGG AGT GAG GAT TCT & 5' GCT TCC TCG ATG CTT CTC TTC \\
\hline PDGF-B & 5' CCC ATT CCC GAG GAG CTT TAT & 5' GAG TGG GAG CGG GTC ATG TTC \\
\hline aFGF & 5' CAG CCC TGA CCG AGA AGT TTA & $5^{\prime}$ GTC CCT TGT CCC ATC CAC TGT \\
\hline bFGF & 5' GGA GAA GAG CGA CCC TCA CAT & 5' GCC AGG TAA CGG TTA GCA CAC A \\
\hline IGF-2 & 5' CCC TCC TGG AGA CGT ACT GTG & $5^{\prime}$ ACG GGG TAT CTG GGG AAG TT \\
\hline KGF & 5' GCA AAT GGC TAC AAA TGT GAA CT & $5^{\prime}$ CAC AAT TCC AAC TGC CAC TGT C \\
\hline
\end{tabular}

IL: interleukin; IFN: interferon; GM-CSF: granulocyte-macrophage colony-stimulating factor; TNF: tumour necrosis factor; TGF: transforming growth factor; EGF: epithelial growth factor; PDGF: platelet-derived growth factor; FGF: fibroblast growth factor; IGF: insulin growth factor; KGF: keratinocyte growth factor.

Cryostat sections, 4-6 $\mu \mathrm{m}$ thick, were fixed in acetone and reacted with appropriate dilutions of antibody. Positive cells were revealed using the Vectastain ABC-alkaline phosphatase system (Vector, Burlingame, CA, USA) and the fast red substrate. To test the specificity of immunostaining, antibodies were omitted or replaced by an isotype-matched control antibody. Under these conditions, no positive cells were identified. The intensity of immunostaining was graded from - (absent) to +++ (strongly positive); complete agreement in scoring was obtained between two independent observers. Furthermore, the immunostaining for each cytokine was quantified by image analysis. The percentage of total surface area of each tissue section occupied by stained cells was determined. The intensity of cytokeratin expression by hyperplastic alveolar pneumocytes in IPF biopsies was evaluated by image analysis. The percentage of the total tissue surface area occupied by hyperplastic

Table 2.-Sequences of probes used for amplification and identification of cytokine complementary deoxyribonucleic acid

\begin{tabular}{ll}
\hline Cytokine & \multicolumn{1}{c}{ Probe } \\
\hline IL-1 $\beta$ & 5' ACA GAT GAA GTG CTC CTT CC \\
IL-6 & 5' AAG GAG ACA TGT AAC AAG AGT \\
IL-8 & 5' GAT GGA AGA GAG CTC TGT CTG \\
IL-10 & 5' TGG ACA ACT TGT TGT TAA AGG \\
IL-15 & 5' GTC ATT TTC TAA CTG AAG CTG \\
IFN- $\gamma$ & 5' AAC TGA CTT GAA TGT CCA ACG \\
GM-CSF & 5' GCT GAG ATG AAT GAA ACA GT \\
TNF- $\alpha$ & 5' TGC TGC ACT TTG GAG TGA T \\
TGF- $\alpha$ & 5' GTG TCC CAT TTT AAT GAC TG \\
TGF- $\beta$ & 5' GAC AGC AGG GAT AAC ACA CT \\
EGF & 5' ACC ACC ACT ATT CCG TAA GA \\
PDGF-A & 5' GTA GGG AGT GAG GAT TCT TTG \\
PDGF-B & 5' TAT GAG ATG CTG AGT GAC CA \\
aFGF & 5' GAA TTA CAA GAA GCC CAA AC \\
bFGF & 5' GTT GTG TCT ATC AAA GGA GTG \\
IGF-2 & 5' TGG AGA CGT ACT GTG CTA CC \\
KGF & 5' GAC CCA AGA GAT GAA GAA TAA \\
\hline
\end{tabular}

IL: interleukin; IFN: interferon; GM-CSF: granulocyte-macrophage colony-stimulating factor; TNF: tumour necrosis factor; TGF: transforming growth factor; EGF: epithelial growth factor; PDGF: plateletderived growth factor; FGF: fibroblast growth factor; IGF: insulin growth factor; KGF: keratinocyte growth factor. pneumocytes was $14.2 \pm 4.3 \%$ in IPF specimens. Such cells were rare in control biopsies.

\section{Statistical methods}

All results are presented as mean \pm SD. For measurement of cytokine cDNAs, all steps of the procedure were performed in parallel for all 10 samples. Comparisons between patients and controls were made using the Mann-Whitney U-test. A p-value of $<0.05$ was considered significant.

\section{Results}

Expression of cytokine $m R N A s$ in lung tissue from patients with IPF and controls

Lung tissue specimens from nonsmoking controls were histologically normal; biopsies from smokers demonstrated the accumulation of pigment-laden macrophages, associated with mild focal fibrotic changes. All lung biopsies from patients

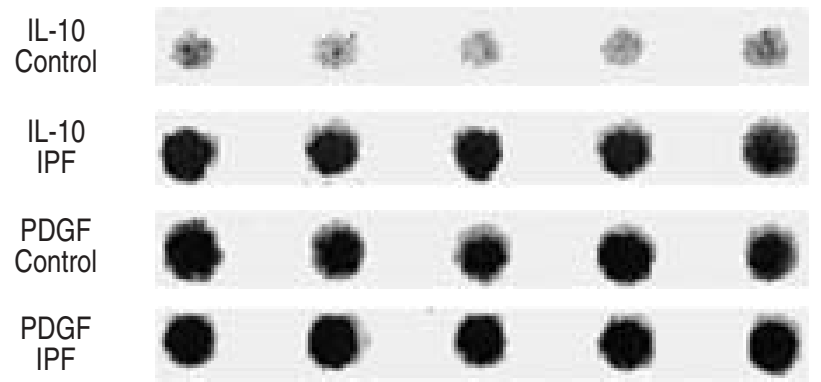

Fig. 1.-Quantification of cytokine complementary deoxyribonucleic acid (cDNA). An equivalent amount of cDNA from each sample was amplified using specific primers for interleukin (IL)-10 or plateletderived growth factor (PDGF). Amplification products were bound to nylon membranes in a dot blot format and hybridised with a radiolabelled probe specific for each cytokine. cDNA for IL-10 was clearly increased in idiopathic pulmonary fibrosis (IPF) specimens compared to that of control lung tissues, whereas similar amounts of cDNA for PDGF were present in the two groups of samples. The amount of radioactivity bound was quantified by electronic autoradiography. 
with IPF showed histological abnormalities typical of UIP, both on paraffin-embedded specimens and frozen sections taken from the samples used for the evaluation of cytokine expression, except that because of their smaller size, the latter specimens contained very limited areas of apparently normal lung tissue. Some variation in the intensity of histopathological abnormalities was observed in the biopsies from different individuals, but all patients had evidence of ongoing active inflammatory and fibrotic reactions.

Examination of PCR products on agarose gels indicated that mRNA coding for all 17 cytokines evaluated in these studies was present in lung tissue from controls and patients with IPF. Indeed, when the amounts of cytokine mRNA present were compared, only mRNAs coding for TGF- $\beta$ and IL-10 were significantly more abundant in IPF specimens than in control lung tissues (fig. $2 ; \mathrm{p}<0.05$ for both cytokines). The levels of mRNA coding for these two cytokines in lung tissue from IPF patients were correlated with each other. However, no correlation was observed between the amounts of mRNA coding for these cytokines and the extent of fibrosis, as assessed by collagen deposition or the intensity of alveolar epithelial hyperplasia evaluated using anticytokeratin immunostaining.

Strikingly, mRNAs coding for all other cytokines evaluated (IL-1 $\beta$, IL-6, IL-8, IL-15, GM-CSF, interferon (IFN)- $\gamma$, TNF- $\alpha$, PDGF-BB, PDGF-AA, IGF-2, fibroblast growth factor $\mathrm{a}(\mathrm{FGF}), \mathrm{bFGF}, \mathrm{TGF}-\alpha, \mathrm{EGF}$ and $\mathrm{KGF}$ ) were expressed in equivalent amounts in fibrotic and control lung tissues (table 3). No evidence for the interdependence of expression of mRNAs for these different cytokines was found.

\section{Expression of TGF- $\beta 1$ and IL-10 in IPF and control lung tissues}

Evaluation of the expression of TGF- $\beta$ and IL-10 on frozen sections from patients with IPF and controls using immunohistochemical techniques confirmed that both cytokines were present in considerably greater amounts in fibrotic lung tissue, as assessed either by semiquantitative evaluation (table 4) or image analysis (IL-10: IPF $11.2 \pm 8.3 \%$, controls $0.6 \pm 0.6 \%$; TGF- $\beta$ : IPF $15 \pm 3.6 \%$, controls $3.9 \pm 0.8 \%$; $<0.05$ for both cytokines). The strikingly increased expression of IL-10 in lung tissue from IPF patients was essentially due to the intense expression of this cytokine by hyperplastic alveolar epithelium (fig. 3a). In these specimens, the distribution of

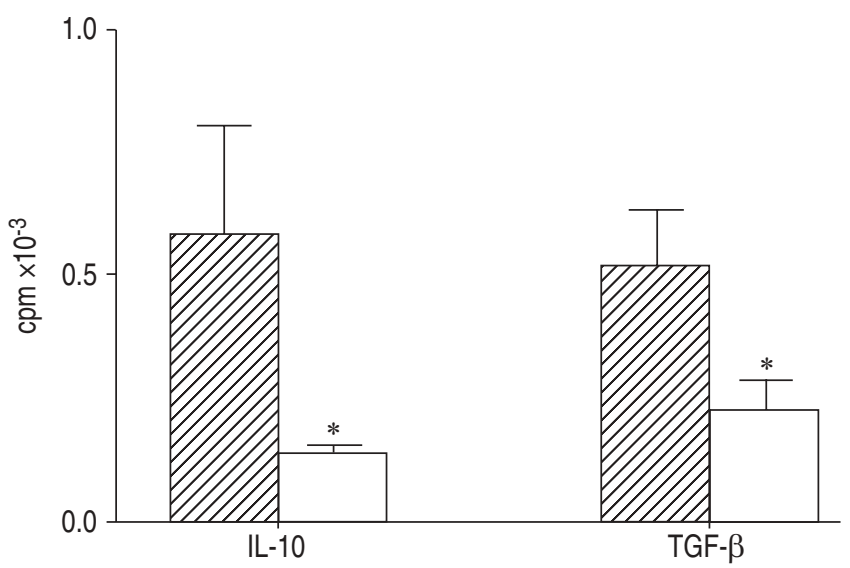

Fig. 2.-Comparison of interleukin (IL)-10 and transforming growth factor (TGF)- $\beta$ messenger ribonucleic acids in lung biopsies from

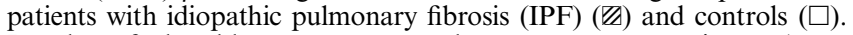
Results of dot blots are presented as counts per minute (cpm; mean \pm SD). *: $\mathrm{p}<0.05$ comparing IPF and controls for both cytokines.
Table 3.-Cytokine messenger ribonucleic acids (mRNAs) expressed in similar amounts in lung tissue from patients with idiopathic pulmonary fibrosis (IPF) and control subjects

\begin{tabular}{lcc}
\hline \multirow{2}{*}{ Cytokine } & \multicolumn{2}{c}{ Expression of cytokine mRNAs } \\
\cline { 2 - 3 } & IPF & Controls \\
\hline PDGF-A & $143 \pm 107$ & $193 \pm 62$ \\
PDGF-B & $2094 \pm 1619$ & $2408 \pm 1331$ \\
aFGF & $252 \pm 340$ & $202 \pm 155$ \\
bFGF & $1650 \pm 2001$ & $1011 \pm 904$ \\
KGF & $1820 \pm 3361$ & $292 \pm 279$ \\
TGF- $\alpha^{\#}$ & $1704 \pm 2706$ & $496 \pm 131$ \\
IGF-2 & $101 \pm 90$ & $107 \pm 54$ \\
EGF & $139 \pm 110$ & $97 \pm 45$ \\
IL-1 $\beta$ & $99 \pm 90$ & $230 \pm 147$ \\
IL-6 & $291 \pm 446$ & $435 \pm 807$ \\
IL-8 & $898 \pm 1602$ & $2890 \pm 1327$ \\
IL-15 & $666 \pm 515$ & $812 \pm 436$ \\
GM-CSF & $168 \pm 133$ & $282 \pm 303$ \\
IFN- $\gamma$ & $235 \pm 185$ & $190 \pm 55$ \\
TNF- $\alpha$ & $457 \pm 279$ & $709 \pm 120$ \\
\hline
\end{tabular}

Results of dot blots for the indicated cytokines are shown for control subjects $(n=5)$ and patients with IPF $(n=5)$, presented as counts per minute \pm SD. PDGF: platelet-derived growth factor; FGF: fibroblast growth factor; KGF: keratinocyte growth factor; TGF: transforming growth factor; IGF: insulin growth factor; EGF: epithelial growth factor; IL: interleukin; GM-CSF: granulocyte-macrophage colonystimulating factor; IFN: interferon; TNF: tumour necrosis factor. ${ }^{\#}$ : a single sample expressed increased amounts of mRNA coding for these cytokines.

the expression of IL-10 could be superimposed on that of epithelial immunostaining for cytokeratin, indicating that IL-10 was almost exclusively expressed by hyperplastic alveolar epithelial cells. Normal alveolar epithelium was only slightly positive for this cytokine (fig. 3b). In both control and fibrotic lung tissues, bronchiolar epithelium, when present, was moderately positive for IL-10, but the intensity of staining of bronchiolar epithelium was similar in the two groups (table 4). It is noteworthy that most pulmonary macrophages were negative for IL-10 expression in all lung tissue specimens.

In contrast to IL-10 expression, a variety of lung cell types expressed TGF- $\beta$ (table 4). Several of these cell types in IPF lung tissue expressed TGF- $\beta$ more intensely than the corresponding population in control specimens. Notably, fibroblasts identified within the connective tissue in the lung of IPF patients were positive for this cytokine. Similarly, both endothelial cells and perivascular smooth muscle clearly stained more intensely for TGF- $\beta$ in the lung of patients with IPF than in controls. In addition, a strong patchy staining for TGF- $\beta$ was noted in the extracellular matrix of biopsies from IPF patients, whereas the connective tissue was only faintly positive in control lung specimens (figs $3 \mathrm{c}$ and $\mathrm{d}$ ). Other cell populations appeared to express similar amounts of TGF- $\beta$ in control and fibrotic lung tissues. This was the case for alveolar macrophages, most of which were clearly positive for TGF- $\beta$. Likewise, both normal and hyperplastic epithelial cells in biopsies from IPF patients and controls stained weakly for TGF- $\beta$. Bronchiolar epithelial cells in all specimens also expressed this cytokine, although the immunostaining was often discontinuous within the same bronchiole.

Expression of cytokines for which $m R N A$ s were present in similar amounts in fibrotic and control lung tissues

Because discrepancies were observed between the expression of cytokines at the mRNA and protein levels, the 
Table 4.-Immunostaining for cytokines in idiopathic pulmonary fibrosis (IPF) and control lung tissue specimens

\begin{tabular}{|c|c|c|c|c|c|c|}
\hline & $\begin{array}{l}\text { Alveolar } \\
\text { epithelium } \#\end{array}$ & $\begin{array}{l}\text { Bronchiolar } \\
\text { epithelium }\end{array}$ & $\begin{array}{c}\text { Alveolar } \\
\text { macrophages }\end{array}$ & $\begin{array}{l}\text { Endothelial } \\
\text { cells }\end{array}$ & $\begin{array}{l}\text { Connective } \\
\text { tissue }\end{array}$ & Lymphocytes \\
\hline \multicolumn{7}{|l|}{ TGF- $\beta$} \\
\hline IPF & + & $+1-$ & $+1++$ & ++ & $+1+$ & $+/-$ \\
\hline Controls & $+/-$ & $+1-$ & $+1++$ & $+/-$ & $+/-$ & $+1-$ \\
\hline \multicolumn{7}{|l|}{ IL-10 } \\
\hline IPF & +++ & ++ & $+/-$ & - & - & - \\
\hline Controls & + & ++ & - & - & - & - \\
\hline \multicolumn{7}{|l|}{ PDGF-BB } \\
\hline IPF & +++ & +++ & + & $+1+$ & $+/-$ & + \\
\hline Controls & + & +++ & + & + & - & + \\
\hline \multicolumn{7}{|l|}{$\mathrm{KGF}$} \\
\hline IPF & +++ & $+1++$ & + & + & $+/-$ & + \\
\hline Controls & + & $+1++$ & + & + & - & + \\
\hline \multicolumn{7}{|l|}{ TGF- $\alpha$} \\
\hline IPF & + & + & +++ & ++ & - & + \\
\hline Controls & $+/-$ & + & +++ & ++ & - & + \\
\hline \multicolumn{7}{|l|}{ GM-CSF } \\
\hline IPF & ++ & $+1+$ & + & + & + & $+1++$ \\
\hline Controls & + & +++ & ++ & + & - & NP \\
\hline
\end{tabular}

Data are presented as - (absent) to $+1+$ (intense) staining and summarise findings for specimens from five patients with IPF and five controls. TGF: transforming growth factor; IL: interleukin; PDGF: platelet-derived growth factor; KGF: keratinocyte growth factor; GM-CSF: granulocytemacrophage colony-stimulating factor; NP: not present. \#: alveolar epithelium was almost always hyperplastic in IPF specimens and normal in control samples.

expression of some of the cytokines present in equivalent amounts at the mRNA level in the lung biopsies from patients with IPF and controls were also evaluated. Consistent with RT-PCR results, little difference in the intensity and distribution of immunostaining for GM-CSF and TGF- $\alpha$ was observed when comparing IPF and control lung tissue (table 4). These results were confirmed by quantitative evaluation using image analysis (GM-CSF: IPF $1.7 \pm 1 \%$, controls $1.6 \pm 1.1 \%$; TGF- $\alpha$ : IPF $3.4 \pm 3.2 \%$, controls $2.5 \pm 0.7 \%$; $>0.2$ for both cytokines).

As indicated above, the levels of mRNA expression for PDGF-BB and KGF were similar when comparing biopsies from IPF patients and controls. For both of these cytokines, the distribution of cytokine expression was similar in the two groups, but some cell types expressed these cytokines more
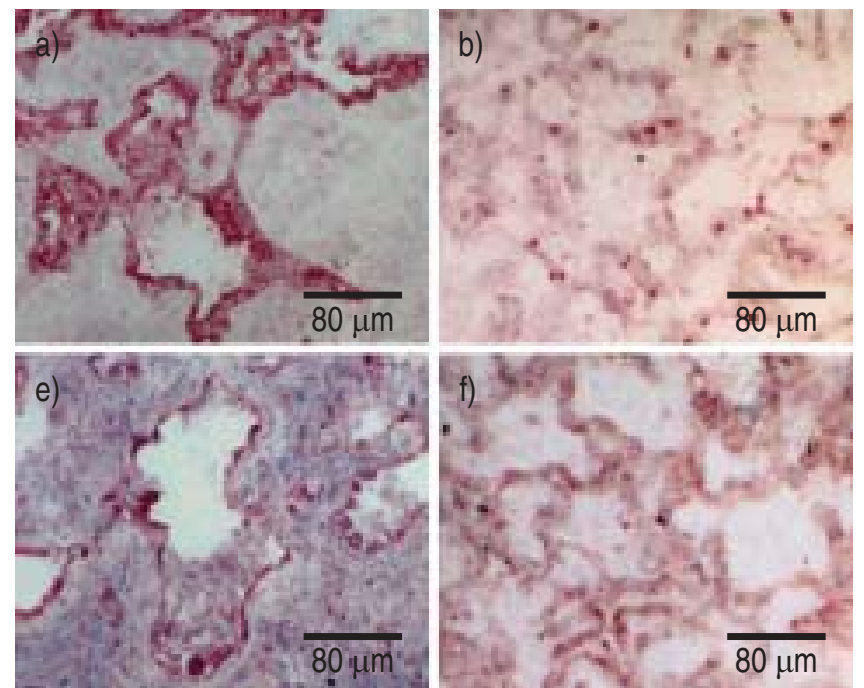

intensely in biopsies from IPF patients than the corresponding populations in control lung tissues, as demonstrated by image analysis (PDGF-BB: IPF $12.5 \pm 2.4 \%$, controls $2.6 \pm 2.4 \%$; KGF: IPF $7.2 \pm 2.4 \%$, controls $1.6 \pm 1 \% ; \mathrm{p}<0.05$ for both cytokines). Thus, hyperplastic alveolar cells (which were essentially absent in control lung tissue), endothelial cells and the perivascular connective tissue of small vessels were more intensively positive for PDGF-BB in IPF specimens (figs 3e and $\mathrm{f}$ ), whereas bronchiolar epithelial cells (intense staining), lymphocytes (weak expression) and alveolar macrophages (weak expression) demonstrated equivalent expression in lung tissue from IPF patients and controls (table 4). Hyperplastic alveolar epithelial cells in specimens from patients with IPF were also stained very strongly for KGF (fig. $3 \mathrm{~g}$ ), whereas

Fig. 3.-Evaluation of cytokine expression in lung tissue from patients with idiopathic pulmonary fibrosis (IPF) and controls using immunohistochemical techniques. Interleukin-10 was strongly expressed by hyperplastic alveolar epithelium in a patient with IPF (a), whereas only scattered epithelial cells were positive in control lung tissue (b). Transforming growth factor- $\beta$ was strongly expressed by the extracellular matrix of lung biopsies from IPF patients (c), whereas the connective tissue was faintly positive in control lung specimens (d). Platelet-derived growth factor (e) and keratinocyte growth factor (g) were strongly expressed by hyperplastic alveolar epithelium in IPF specimens, whereas alveolar macrophages were less strongly stained, and both cytokines were weakly expressed in control lung tissues (f and $h$ ). 
bronchial epithelial cells and alveolar epithelial cells in control biopsies demonstrated only weak-to-moderate staining (fig. 3h). Alveolar macrophages, endothelial cells and lymphocytes were slightly positive for this cytokine in both types of lung tissue (table 4).

\section{Discussion}

In the present study, evaluation of the cytokine profiles in the lungs of IPF patients and controls found the following. 1) mRNAs coding for all cytokines studied were detectable in control lung tissue. 2) Among the 17 cytokines studied, only mRNAs coding for TGF- $\beta$ and IL-10 were clearly more abundant in biopsies from patients with IPF than in lung tissue from controls. 3) Immunohistochemical techniques confirmed the increased expression of these two cytokines at the protein level in IPF, but also showed increased amounts of PDGF-BB and KGF. Each of these cytokines was produced by specific cell populations, whose abundance was variable in the different biopsies because of the heterogeneity of the fibrotic reaction in the biopsies. 4) Hyperplastic alveolar epithelial cells, an abundant cell population in lung biopsies from IPF, appear to be an important source of cytokines capable of regulating fibrotic reactions.

Although several studies have suggested that cytokines are involved in the pathogenesis of IPF, the amounts of mRNA coding for these mediators have seldom been quantitatively compared in biopsies from patients with IPF and control subjects [12-14]. The current data indicate that all the cytokines evaluated can be detected in control lung tissue and that the amounts of mRNAs coding for most of these cytokines are not significantly increased in the lungs of patients with IPF. However, because the number of specimens studied was small, the possibility that a difference between IPF and control specimens could have been missed for cytokines with variable mRNA expression (e.g. KGF, TGF- $\alpha$ ) cannot be excluded. Furthermore, it should be noted that these results reflect only a given moment during the evolution of the disease and do not exclude the possibility that the accumulation of mRNA coding for some of these factors could be increased during other stages of the process. For example, in the animal model of pulmonary fibrosis induced by bleomycin, TNF- $\alpha$, IL- 6 and GM-CSF are increased during the initial inflammatory stage of the reaction but return to normal when fibroproliferative processes and collagen deposition predominate [15-18]. However, the current authors believe that from a clinical point of view the results obtained here are significant, since the specimens evaluated were representative of the population of patients with IPF at the time an open lung biopsy was performed to establish the diagnosis.

In this context, the observation that increased amounts of mRNAs coding for TGF- $\beta$ and IL-10 are present in IPF is of particular interest. Increased expression of TGF- $\beta$ at the protein and mRNA level in the lung of patients with IPF has been reported previously [19], the findings of which are fully confirmed in this study. The critical role of this cytokine in pulmonary fibrosis has been reinforced by studies using animal models, which have demonstrated that the inhibition of the actions of this cytokine prevents or reduces the deposition of collagen in the lung [20].

Strikingly, IL-10 was the only other cytokine identified for which mRNA was found to be more abundant in lung tissue from IPF patients than that from controls. The potential role of this cytokine in IPF has received much less attention than that of TGF- $\beta$. An increase in the production of IL-10 mRNA by alveolar macrophages recovered from bronchoalveolar lavage (BAL) in patients with IPF has been reported, but the amount of IL-10 protein in cell-free BAL fluid was found to be lower [21] or slightly increased [22] in these patients when compared with BAL fluid from healthy controls. Furthermore, the production of this cytokine by fibrotic lung tissue has not been evaluated. The present findings demonstrate that hyperplastic epithelial cells are by far the most important source of the increased IL-10 expression in the lung of patients with IPF. This finding is compatible with the previous observation that normal pulmonary epithelial cells also produce small amounts of this cytokine [23] and that the in vitro activation of other epithelial cells (e.g. keratinocytes) results in the production of substantial amounts of IL-10 [24].

The precise role of IL-10 in IPF remains to be established. In general, this cytokine is considered to be an antiinflammatory factor and, thus, it could be speculated that the production of IL-10 in IPF serves to downregulate the inflammatory reaction associated with this disorder [25]. IL10 may exert other, nonmutually exclusive effects. Thus, this cytokine was shown to inhibit collagen synthesis in vitro using different fibroblastic cell types [26, 27]. However, the effects of IL-10 on tissue fibrosis in vivo are variable and seem to depend on the experimental model used. For example, IL-10 inhibited bleomycin-induced lung injury when assessed by the hydroxyproline contents of the whole lung of mice [27], whereas, lung collagen deposition was found to be decreased in IL-10 knockout mice following silica-induced pulmonary fibrosis [28] and the persistence of local production of IL-10 in the lung of wild-type mice was suggested to promote the development of pulmonary fibrosis [28]. Finally, IL-10 is known to facilitate the development of immune responses producing a T-helper 2 cytokine profile, as has been observed in IPF [29]. Thus, additional studies are needed to precisely determine the effects of IL-10 in fibrotic processes, since the modulation of the production of this cytokine may be of interest for the treatment of patients with IPF.

For most of the cytokines evaluated (i.e. TGF- $\beta$, IL-10, GM-CSF and TGF- $\alpha$ ), evaluation of cytokine expression at the mRNA and protein level gave concordant results. Nevertheless, the immunohistochemical findings for PDGF-BB and KGF point out the importance of evaluating cytokine expression at both the mRNA and protein levels. Thus, although mRNAs coding for PDGF-BB and KGF were expressed in similar amounts in IPF and control tissue, evidence for localised accumulation of both factors was observed in IPF by immunohistochemical techniques. Post-transcriptional regulation or enhanced post-translational stability of these cytokines in IPF could explain these discrepancies. For example, PDGF mRNA has been shown to contain an internal ribosome entry segment that is capable of enhancing the translation of this factor and the binding of PDGF to matrix components may prolong its tissue half-life [30]. In addition, these cytokines were shown to be produced by many cell types in the normal lung, whereas increased production in IPF was restricted to only some of these populations. Under these conditions, increased transcription by a minority cell type could remain undetected when evaluating mRNA extracted from total lung.

The dominant effect of PDGF-BB is to stimulate fibroblast proliferation and migration and prior studies have shown the presence of this factor in the lung of patients with IPF [5, 7, 12]. Consistent with the findings of Homma et al. [31], it was found in this study that the increased expression of PDGF-BB in IPF is particularly important in hyperplastic epithelium and, to a lesser degree, fibroblasts and smooth-muscle cells.

KGF is a critical growth factor for alveolar epithelial cells and plays an essential role in repair of lung damage [32, 33]. Although normal rat lung has been shown to constitutively express KGF [32], to the current authors' knowledge the expression of this factor has not been reported previously in normal human lung. Here it is demonstrated that mRNA for 
KGF can be detected in normal lung and that normal alveolar macrophages are positively stained with antibodies directed against this factor. Furthermore, although the mRNA expression for KGF was not significantly different between fibrotic and control lung tissues, hyperplastic alveolar epithelium in lung parenchyma from patients with IPF was intensely positive for this mediator. Since KGF is an important factor for proliferation and differentiation for type II pneumocytes and induces alveolar hyperplasia [32], the current results suggest that this cytokine, produced locally by epithelial cells, may participate in alveolar repair through autocrine or paracrine effects.

Taken together, the information presented here provides a variety of new insights into the cytokines produced in the lung in idiopathic pulmonary fibrosis and emphasises the potential importance of transforming growth factor- $\beta$ and interleukin10 in the pathogenesis of this disease. An important goal for future research is the application of this information to the development of new therapeutic strategies. In this context, it has been suggested that the administration of interferon- $\gamma$ may lead to functional improvement of patients with idiopathic pulmonary fibrosis [34]. It is interesting to note that the response to interferon- $\gamma$ was shown to correlate with a decrease in transforming growth factor- $\beta$ messenger ribonucleic acid in the lung of these patients and that interferon- $\gamma$ is known to antagonise the production of T-helper 2 cytokines in vitro. Thus, other strategies designed to modulate the production of these cytokines may offer new avenues for the treatment of this very disabling disease.

\footnotetext{
Acknowledgements. The authors would like to thank M.F. Millot for excellent technical assistance.
}

detection in tissue sections. Histochem $J$ 1979; 11: 447455 .

11. Bergeron A, Bonay M, Kambouchner M, et al. Cytokine patterns in tuberculous and sarcoid granulomas: correlations with histopathologic features of the granulomatous response. J Immunol 1997; 159: 3034-3043.

12. Antoniades HN, Bravo MA, Avila RE, et al. Platelet-derived growth factor in idiopathic pulmonary fibrosis. $J$ Clin Invest 1990; 86: 1055-1064.

13. Broekelmann TJ, Limper AH, Colby TV, McDonald JA. Transforming growth factor $\beta 1$ is present at sites of extracellular matrix gene expression in human pulmonary fibrosis. Proc Natl Acad Sci USA 1991; 88: 6642-6646.

14. Piguet PF, Ribaux C, Karpuz V, Grau GE, Kapanci Y. Expression and localization of tumor necrosis factor-alpha and its mRNA in idiopathic pulmonary fibrosis. Am J Pathol 1993; 143: 651-655.

15. Phan SH, Kunkel SL. Lung cytokine production in bleomycin-induced pulmonary fibrosis. Exp Lung Res 1992; 18: $29-43$

16. Scheule RK, Perkins RC, Hamilton R, Holian A. Bleomycin stimulation of cytokine secretion by the human alveolar macrophage. Am J Physiol 1992; 262: L386-L391.

17. Smith RE, Strieter RM, Phan SH, Lukacs N, Kunkel SL. TNF and IL-6 mediate MIP- $1 \alpha$ expression in bleomycininduced lung injury. J Leukoc Biol 1998; 64: 528-536.

18. Andreutti D, Gabbiani G, Neuville P. Early granulocytemacrophage colony-stimulating factor expression by alveolar inflammatory cells during bleomycin-induced rat lung fibrosis. Lab Invest 1998; 78: 1493-1502.

19. Khalil N, Greenberg AH. The role of TGF- $\beta$ in pulmonary fibrosis. Ciba Found Symp 1991; 157: 194-207.

20. Nakao A, Fujii M, Matsumura R, et al. Transient gene transfer and expression of $\operatorname{Smad} 7$ prevents bleomycininduced lung fibrosis in mice. J Clin Invest 1999; 104: 5-11.

21. Martinez JA, King TE Jr, Brown $\mathrm{K}$, et al. Increased expression of the interleukin-10 gene by alveolar macrophages in interstitial lung disease. Am J Physiol 1997; 273 L676-L683.

22. Moller DR, Forman JD, Liu MC, et al. Enhanced expression of IL-12 associated with Th1 cytokine profiles in active pulmonary sarcoidosis. J Immunol 1996; 156: 4952-4960.

23. Tazi A, Moreau J, Bergeron A, Dominique S, Hance AJ, Soler P. Evidence that Langerhans cells in adult pulmonary Langerhans cell histiocytosis are mature dendritic cells: importance of the cytokine microenvironment. J Immunol 1999; 163: 3511-3515.

24. Becherel PA, LeGoff L, Frances C, et al. Induction of IL-10 synthesis by human keratinocytes through CD23 ligation: a cyclic adenosine 3',5'-monophosphate-dependent mechanism. J Immunol 1997; 159: 5761-5765.

25. Moore KW, de Waal Malefyt R, Coffman RL, O'Garra A. Interleukin-10 and the interleukin-10 receptor. Annu Rev Immunol 2001; 19: 683-765.

26. Reitamo S, Remitz A, Tamai K, Uitto J. Interleukin-10 modulates type I collagen and matrix metalloprotease gene expression in cultured human skin fibroblasts. J Clin Invest 1994; 94: 2489-2492.

27. Arai $\mathrm{T}$, Abe $\mathrm{K}$, Matsuoka $\mathrm{H}$, et al. Introduction of the interleukin-10 gene into mice inhibited bleomycin-induced lung injury in vivo. Am J Physiol Lung Cell Mol Physiol 2000; 278: L914-L922.

28. Huaux F, Louahed J, Hudspith B, et al. Role of interleukin10 in the lung response to silica in mice. Am J Respir Cell Mol Biol 1998; 18: 51-59.

29. Lukacs NW, Hogaboam C, Chensue SW, Blease K, Kunkel $\mathrm{SL}$. Type 1/type 2 cytokine paradigm and the progression of pulmonary fibrosis. Chest 2001; 120: 5S-8S.

30. Willis AE. Translational control of growth factor and protooncogene expression. Int J Biochem Cell Biol 1999; 31: 73-86.

31. Homma S, Nagaoka I, Abe H, et al. Localization of plateletderived growth factor and insulin-like growth factor I in the
10. Junqueira LC, Bignolas G, Brentani RR. Picrosirius staining plus polarization microscopy, a specific method for collagen 
fibrotic lung. Am J Respir Crit Care Med 1995; 152: 2084 2089.

32. Ulich TR, Yi ES, Longmuir K, et al. Keratinocyte growth factor is a growth factor for type II pneumocytes in vivo. J Clin Invest 1994; 93: 1298-1306.

33. Sugahara K, Iyama K, Kuroda MJ, Sano K. Double intratracheal instillation of keratinocyte growth factor prevents bleomycin-induced lung fibrosis in rats. $J$ Pathol 1998; 186: 90-98.

34. Ziesche R, Hofbauer E, Wittmann K, Petkov V, Block LH. A preliminary study of long-term treatment with interferon $\gamma-1 \mathrm{~b}$ and low-dose prednisolone in patients with idiopathic pulmonary fibrosis. $N$ Engl J Med 1999; 341: 1264 1269. 